ARTIGO

\title{
ANÁLISE NUMÉRICA DE LIGAÇÃO PARAFUSADA SEMIRRÍGIDA EM PERFIS FORMADOS A FRIO ${ }^{1}$
}

\author{
Emerson Cardoso de Castro ${ }^{2}$ \\ Flávio Teixeira de Souza \\ Arlene Maria Cunha Sarmanho
}

\begin{abstract}
RESUMO
O presente trabalho constitui-se de uma análise numérica, por meio de elementos finitos, objetivando a reprodução via software de um ensaio experimental de ligação parafusada semirrígida em perfis formados a frio, dada no âmbito tridimensional. A análise consistiu-se a partir da reprodução da geometria do protótipo, das condições de contorno e aplicação de carregamento. Para melhor previsão do comportamento da ligação, foram inseridas ao modelo a não linearidade física e geométrica. Foram obtidas as curvas força-deslocamento e a evolução das tensões de Von Mises para os diferentes componentes do protótipo. Os resultados indicaram que o modelo numérico é cerca de duas vezes mais rígido que o experimental. Todavia, foi possível observar que o comportamento do modelo numérico possui tendência similar ao do modelo experimental e também foi possível avaliar a contribuição dos elementos da ligação para o desempenho da mesma.
\end{abstract}

Palavras-chave: Análise numérica. Ligação parafusada semirrígida. Perfis formados a frio. Desempenho estrutural.

\section{INTRODUÇÃO}

Os perfis formados a frio ou comumente conhecimentos como perfis dobrados são elementos constituídos de chapas finas, obtidos por meio de processo de dobramento ou por conformação contínua, através de tiras cortadas de chapas ou bobinas (ABNT NBR 14762, 2010; YU, 2000).

A ligação, por sua vez, é definida como o componente físico que mecanicamente conecta os elementos estruturais, pela qual é possível transferir força e/ou momento fletor de um elemento estrutural aos elementos de suporte. Por meio delas, pode haver formas distintas de união entre as peças, podendo ser comumente classificadas como ligações parafusadas, ligações soldadas e ligações de encaixe (LEE et al., 2014), conforme as Figuras 1, 2 e 3.

\footnotetext{
${ }^{1}$ Como citar este artigo: CASTRO, Emerson Cardoso de; SOUZA, Flávio Teixeira de; SARMANHO, Arlene Maria Cunha. Análise numérica de ligação parafusada semirrígida em perfis formados a frio. ForScience: revista científica do IFMG, Formiga, v. 7, n. 2, e00652, jul./dez. 2019. DOI: 10.29069/forscience.2019v7n2.e652.
}

\footnotetext{
${ }^{2}$ Autor para correspondência: Emerson Cardoso de Castro, e-mail: emersoncastro@ outlook.com.
} 


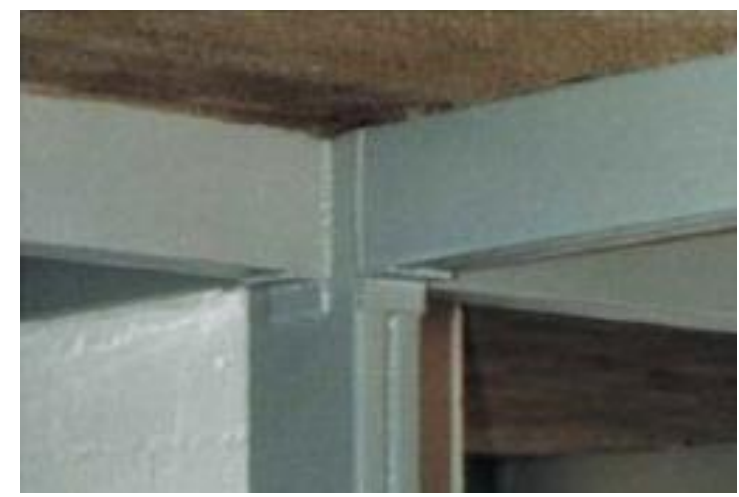

Figura 1 - Ligação viga-coluna por meio de solda Fonte: Silva et al. (2007).

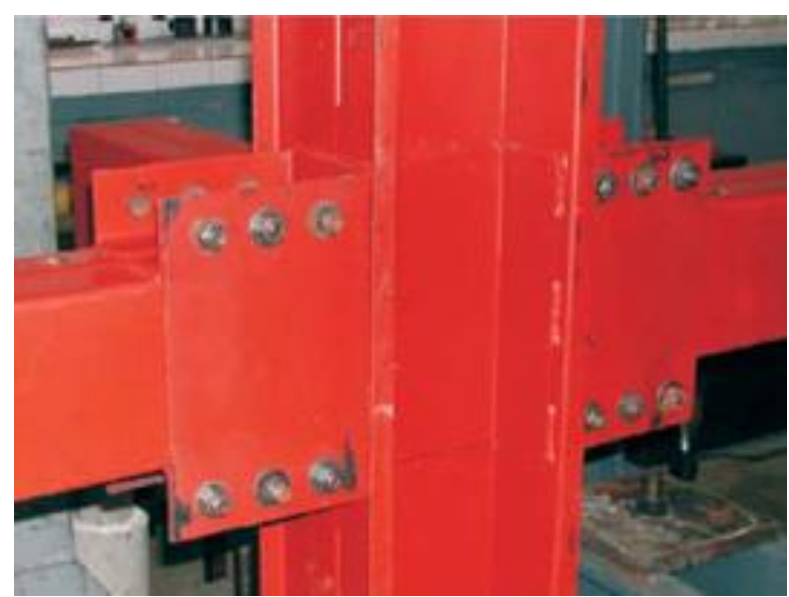

Figura 2 - Ligação viga-coluna por meio de parafusos Fonte: Silva e Freitas (2008).

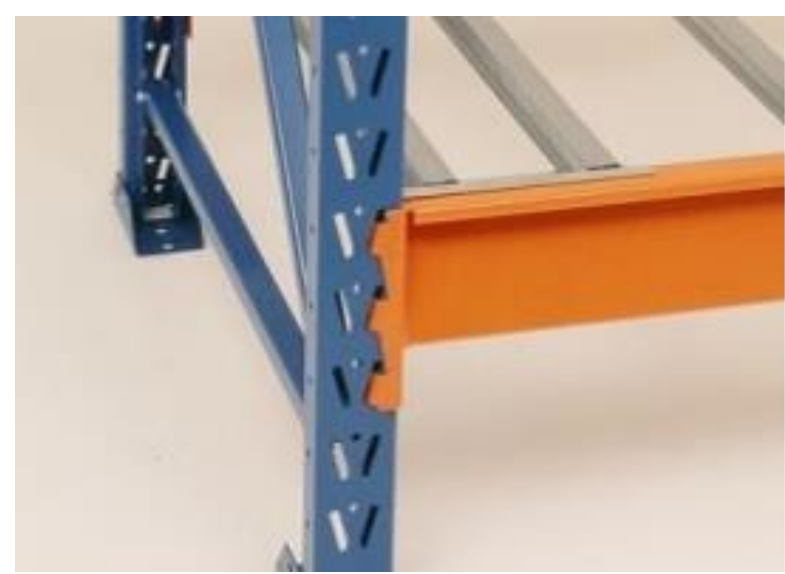

Figura 3 - Ligação viga-coluna por meio de encaixe Fonte: Machado (2018).

A ligação parafusada é um dos tipos mais utilizados, devido à esbelteza dos perfis formados a frio. Essas mesmas oferecem vantagens na montagem por maior rapidez. Este tipo de ligação pode requerer componentes secundários para fixação e a presença desses 
componentes pode conferir melhor rigidez à ligação e consequentemente melhor resistência. As ligações soldadas fornecem juntas rígidas entre os membros conectados; elas promovem maior economia pois, em certos casos, eliminam a necessidade de elementos secundários. A rigidez e resistência desse tipo de ligação dependem da geometria das estruturas e da forma que estão conectadas. Já as ligações de encaixe são semicontínuas, sua união é feita sem a presença de parafusos ou solda e sim por meio de "garras"; são comumente utilizadas em sistemas de armazenamento industrial, promovem flexibilidade na disposição da estrutura e, ao mesmo tempo, conferem maior rigidez e resistência lateral aos quadros (LEE et al., 2014).

É importante salientar que as ligações idealizadas, rígidas ou flexíveis, apresentam respostas estruturais diferentes dos resultados obtidos por meio da condição real, em que as ligações transmitem momentos ou são submetidas a algum tipo de rotulação, apresentando, cada uma, rigidez intermediária (SILVA, 2006).

A ligação rígida ou engastada promove a continuidade da estrutura e é garantida se as rotações relativas são totalmente restringidas, ou admitem restrição mínima ou igual a 90\% da rotação teórica, verificada sob condição de rótula ideal, caracterizando uma ligação resistente a momento fletor. Na ligação flexível ou rotulada, as rotações relativas entre os elementos conectados não são restringidas ou admitem uma restrição máxima ou igual a $20 \%$ da rotação relativa teórica, verificada sob condição de rótula ideal, caracterizando uma ligação com pouca ou sem nenhuma resistência a momento fletor. As outras ligações situadas entre esses dois extremos constituem as ligações semirrígidas (AISC, 2016), conforme mostram as Figuras 4, 5 e 6.

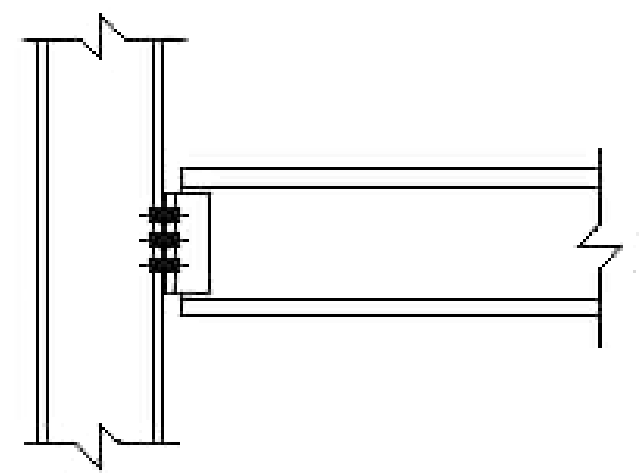

Figura 4 - Ligação viga-coluna flexível Fonte: Santos (1998).

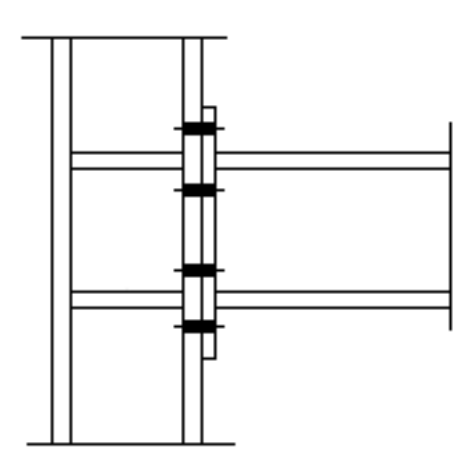

Figura 5 - Ligação viga-coluna rígida Fonte: Santos (1998). 


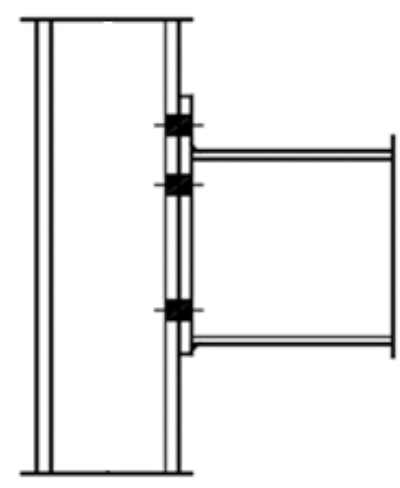

Figura 6 - Ligação viga-coluna semirrígida Fonte: Silva (2017).

Nesse contexto, o estudo de ligações torna-se bastante abrangente devido à complexidade de cada sistema, sendo necessárias análises numéricas e experimentais para prever o comportamento e a eficiência das ligações. Com esse intuito, é comum o desenvolvimento de modelos numéricos que representem o comportamento da estrutura, fornecendo subsídios para melhor compreensão, varredura dos resultados e verificação de possíveis falhas no modelo analisado. Este procedimento é economicamente mais viável, devido ao alto custo dos ensaios experimentais (CASTRO, 2018).

Dessa forma, este trabalho objetiva desenvolver um modelo numérico que represente a ligação parafusada semirrígida em perfis formados a frio, verificar a viabilidade da análise do comportamento da ligação, avaliar a evolução das tensões de Von Mises e comparar os resultados dos deslocamentos obtidos no modelo numérico com os do modelo experimental.

\section{DESENVOLVIMENTO}

\subsection{Análise experimental}

Este trabalho consistiu no estudo da ligação parafusada semirrígida proposta no trabalho experimental de Silva (2006), que avaliou experimentalmente o sistema de ligação entre perfis formados a frio, concebida pelo projeto habitacional USIHAB (2001) (MORAIS, 2003) de empresa nacional do setor. A importância do estudo dessa ligação parafusada, está na redução no tempo de montagem, viabilidade de execução e a geometria da ligação possibilitarem melhor compatibilidade com os sistemas de vedações da edificação.

O protótipo analisado é composto por uma coluna de seção I enrijecida, feita de perfis

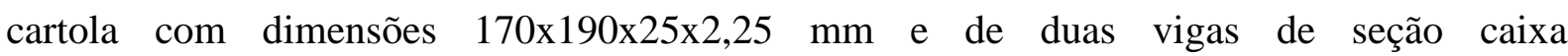


150x120x20x2,00 mm. Os elementos de ligação utilizados na conexão são cantoneiras soldadas às vigas, suportes em U soldados aos flanges da coluna e reforços soldados aos flanges e ao contorno interno da coluna.

O método de ligação para unir as vigas à coluna por meio dos elementos de ligação cantoneiras e suporte são os parafusos. Para cada viga, são utilizados 12 parafusos, perfazendo um total de 24 parafusos com 12,50 mm de diâmetro em cada ligação. A Figura 7 mostra a perspectiva da geometria do modelo analisado experimentalmente.

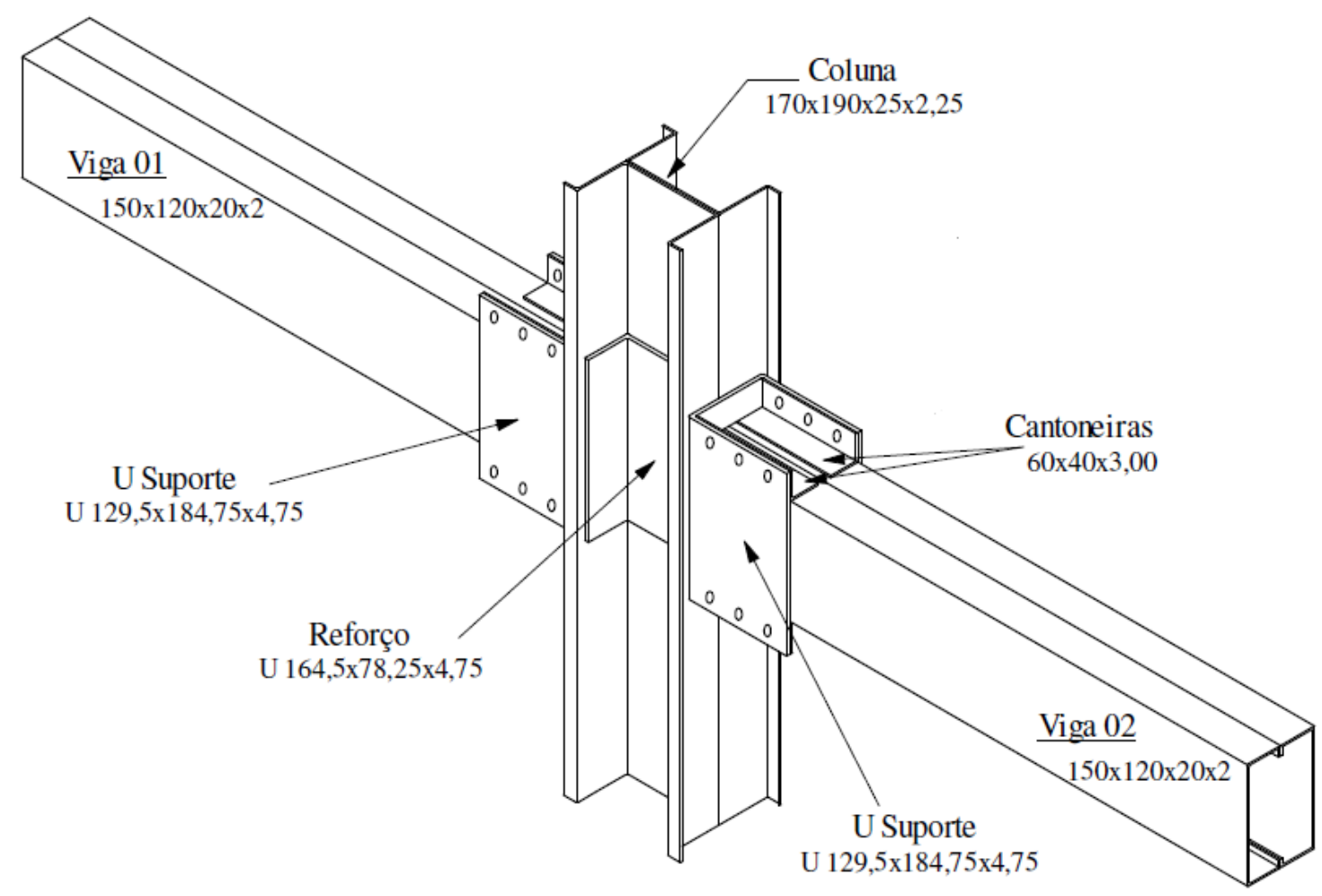

Figura 7 - Perspectiva da geometria do modelo analisado Fonte: Castro (2018).

A análise experimental de Silva (2006) consistiu no ensaio do modelo acima com a aplicação de força na extremidade de cada viga. Conforme Tabela 1, a força última aplicada atingiu o valor de $17,06 \mathrm{kN}$ e representou o início da plastificação da estrutura, nesse momento os deslocamentos verticais nas extremidades das vigas 1 e 2 atingiram 31,94 mm e 34,33 mm respectivamente. Devido à magnitude das deformações e deslocamentos, o desempenho da ligação correspondeu ao comportamento semirrígido. 
Tabela 1 - Principais resultados obtidos na análise experimental de Silva (2006)

\begin{tabular}{ccc}
\hline Ligação & $\begin{array}{c}\text { Força última experimental } \\
(\mathbf{k N})\end{array}$ & $\begin{array}{c}\text { Deslocamento vertical nas } \\
\text { extremidades das vigas }(\mathbf{m m})\end{array}$ \\
\hline viga 1 - coluna & 17,06 & 31,94 \\
viga 2 - coluna & 17,06 & 34,33 \\
\hline
\end{tabular}

Fonte: Silva (2006).

\subsection{Análise numérica}

Neste trabalho foi desenvolvido um modelo numérico, via software ANSYS, que simulou o comportamento da ligação estudada por Silva (2006). Foram utilizadas operações da linguagem paramétrica do ANSYS (APDL) (ANSYS, 2013) no desenvolvimento deste trabalho.

\subsubsection{Definição da geometria e malha do modelo numérico}

O primeiro passo foi o desenvolvimento da geometria do modelo numérico reproduzindo todos os seus componentes.

Para construção da malha de elementos finitos no programa ANSYS, foram utilizados elementos de casca (shell181) para todos os elementos da estrutura, exceto para as vigas que tiveram um trecho também modelado em elementos de barra (beam188), conforme mostra a Figura 8. A utilização do elemento de viga deu-se para evitar possíveis efeitos localizados que comprometem a precisão do modelo numérico e também para acelerar o processo de convergência numérica.

A definição da malha deu-se de forma a garantir precisão e eficiência computacional (SOUZA, 2013). Foram realizados testes utilizando a malha com distintos tamanhos, onde verificou-se que os tamanhos muito reduzidos poderiam comprometer o processo de convergência do modelo numérico. Dessa forma, considerou-se para os elementos sem furos, a malha quadrangular de aproximadamente $20 \mathrm{~mm}$. No caso dos elementos com furos, considerou-se malha triangular de aproximadamente $10 \mathrm{~mm}$ para facilitar o ajuste da malha às bordas circulares dos mesmos. Nos elementos de barra das vigas, a subdivisão do trecho linear deu-se em 20 elementos ao longo do seu comprimento, conforme as Figuras 8 e 9. Verificou-se também que os tamanhos da malha adotados não comprometeriam a precisão dos resultados. 


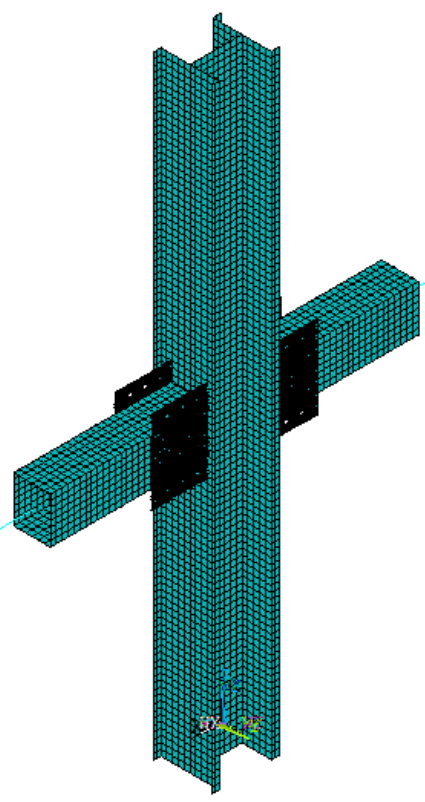

(a)

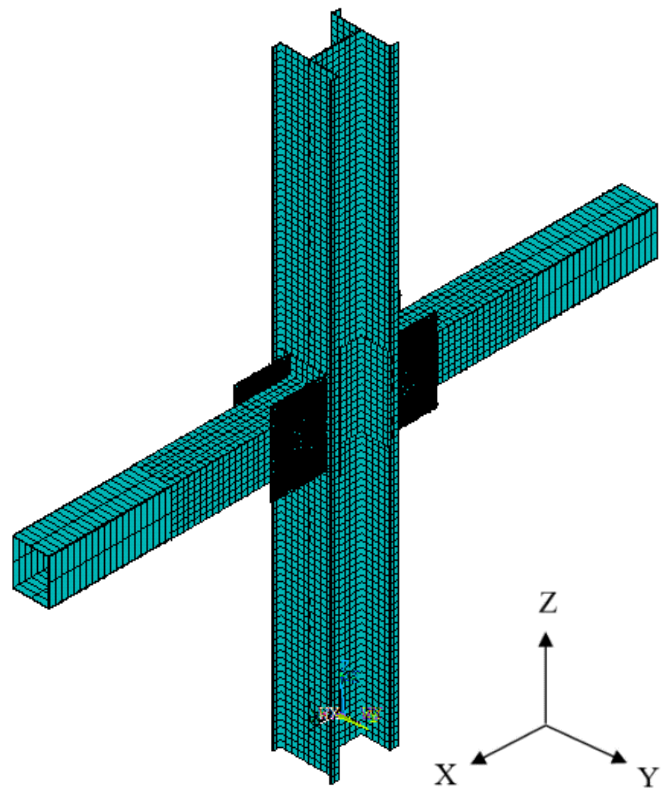

(b)

Figura 8 - Perspectiva da estrutura com malha Fonte: Castro (2018).

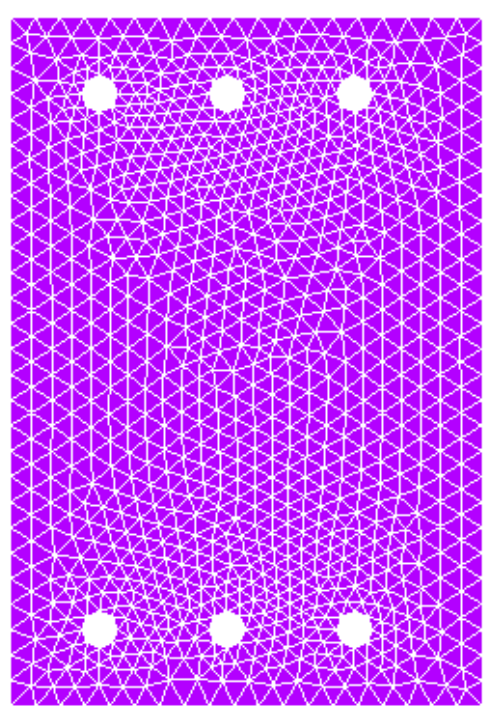

(a)

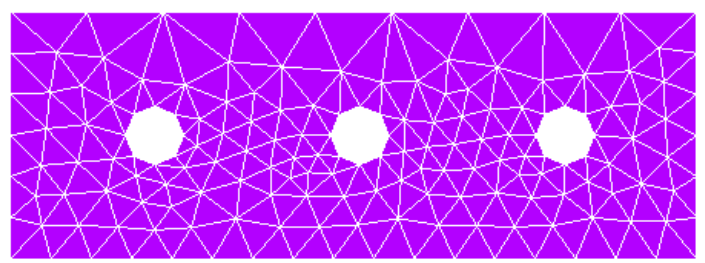

(b)

Figura 9 - Vista dos elementos com furos e com malha, U suporte (a) e cantoneiras (b) Fonte: Castro (2018).

Toda a estrutura foi modelada em dimensões reais conforme modelo experimental. Para as vigas, foi utilizada a simplificação adotando uma seção tubular retangular, considerando as mesmas dimensões de largura e altura da seção das vigas e uma espessura de 2,366 mm que produzisse um momento de inércia equivalente à seção tipo "caixa" utilizada no experimento. A alma do perfil $U$ suporte, paralela à mesa da coluna, foi modelada 
considerando o somatório das espessuras desses elementos na região da ligação entre os mesmos. A aba da cantoneira paralela à mesa da viga foi modelada considerando o somatório das espessuras desses elementos na região da ligação entre os mesmos. O reforço foi modelado considerando o somatório das espessuras entre os elementos da região da ligação com a coluna (Figura 10).

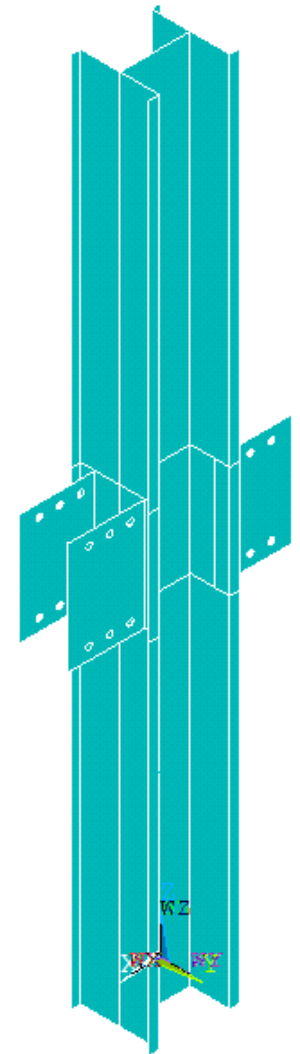

(a)

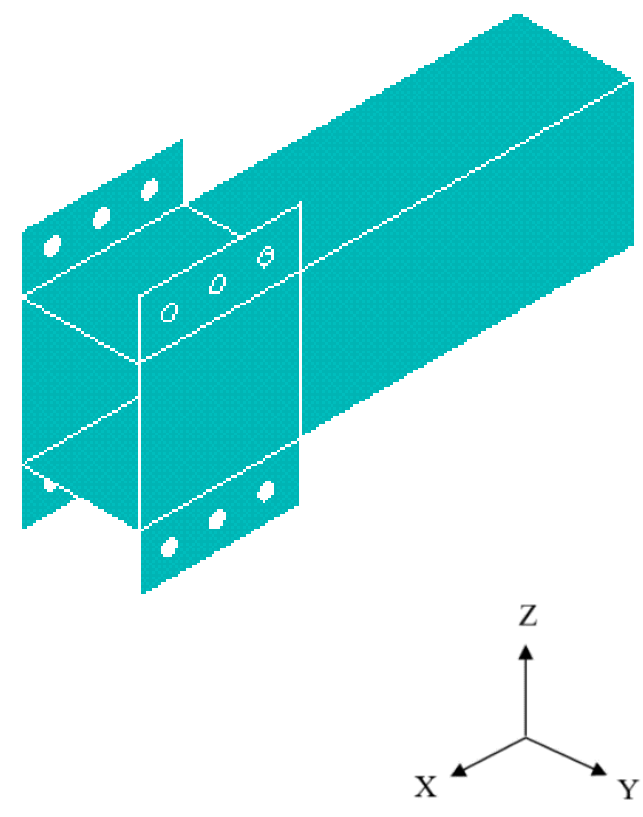

(b)

Figura 10 - Perspectiva dos elementos modelados em elementos de casca Fonte: Castro (2018).

\subsubsection{Propriedades dos materiais}

As propriedades do aço foram introduzidas no modelo por meio da aproximação bilinear do diagrama tensão-deformação, com as propriedades apresentadas na Tabela 2. 
Tabela 2 - Valores de bilinearidade

\begin{tabular}{ccccc}
\hline Perfis & $\mathbf{f}_{\mathbf{y}}(\mathbf{M P a})$ & $\mathbf{f}_{\mathbf{u}}(\mathbf{M P a})$ & $\mathbf{E}(\mathbf{M P a})$ & $\boldsymbol{v}$ \\
\hline Coluna & 385,8 & 515,4 & $200.000,0$ & 0,3 \\
Vigas & 385,8 & 515,4 & $200.000,0$ & 0,3 \\
U suporte & 250,0 & 400,0 & $200.000,0$ & 0,3 \\
Cantoneiras & 250,0 & 400,0 & $200.000,0$ & 0,3 \\
\hline
\end{tabular}

Fonte: Castro (2018).

\subsubsection{Definição das condições de contorno e carregamento}

Para simular a interação dos parafusos entre os furos das cantoneiras e U suporte, utilizou-se o comando de acoplamento de nós coincidentes, o qual considera, nos respectivos nós, um ponto de conexão, igualando seus deslocamentos de translação nas direções X, Y e Z, conforme Figura 11a.

$\mathrm{O}$ acoplamento do $\mathrm{U}$, suporte à mesa da coluna, também se deu acoplando-se os deslocamentos. Nessa fase, além dos vínculos relativos às translações, também foram aplicados vínculos referentes às rotações ROTX, ROTY e ROTZ, o que possibilita a transferência de esforços como momento fletor entre a ligação e a coluna (Figura 11 b).

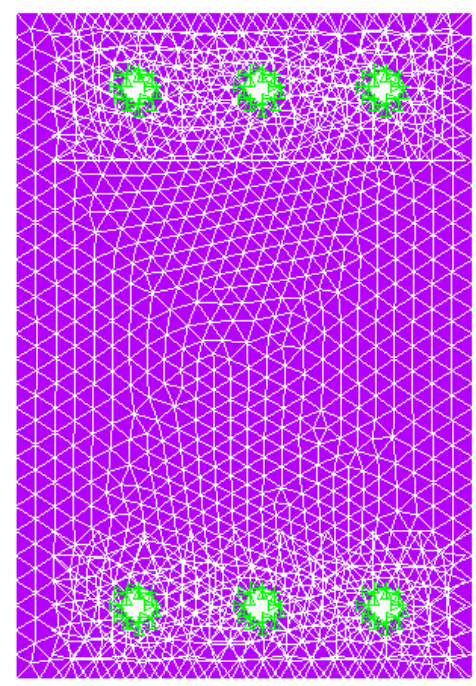

(a)

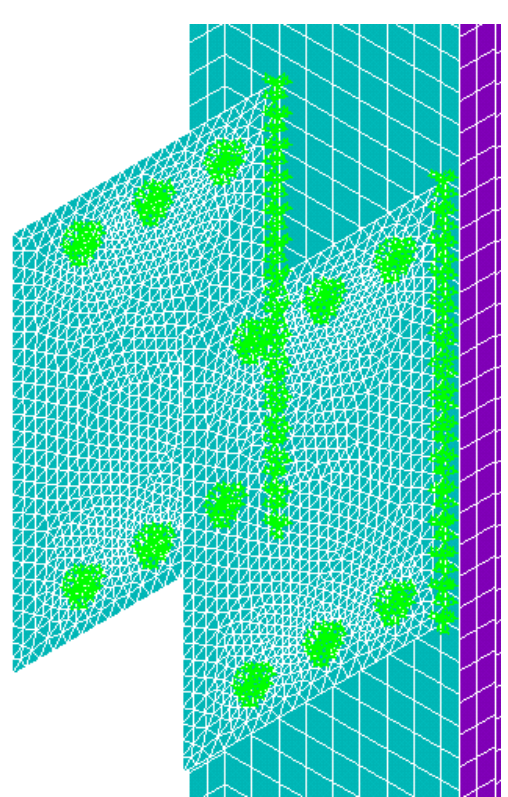

(b)

Figura 11 - Detalhes dos componentes da ligação após aplicação do comando de acoplamento Fonte: Castro (2018). 
Para estabelecer a continuidade na interface entre os elementos de casca e de barra na viga, utilizou-se o comando CERIG, o qual cria uma região rígida. Na aplicação desse comando, seleciona-se o nó mestre da extremidade do elemento de barra localizado no centroide da seção tipo caixa e o conjunto de nós do perímetro da seção, os quais serão os nós dependentes. O nó mestre controlará o comportamento dos nós no entorno da região rígida, onde todos os nós que circundam se deformarão de igual valor, atribuindo àquela interface de seções uma configuração totalmente rígida, ver Figura 12.
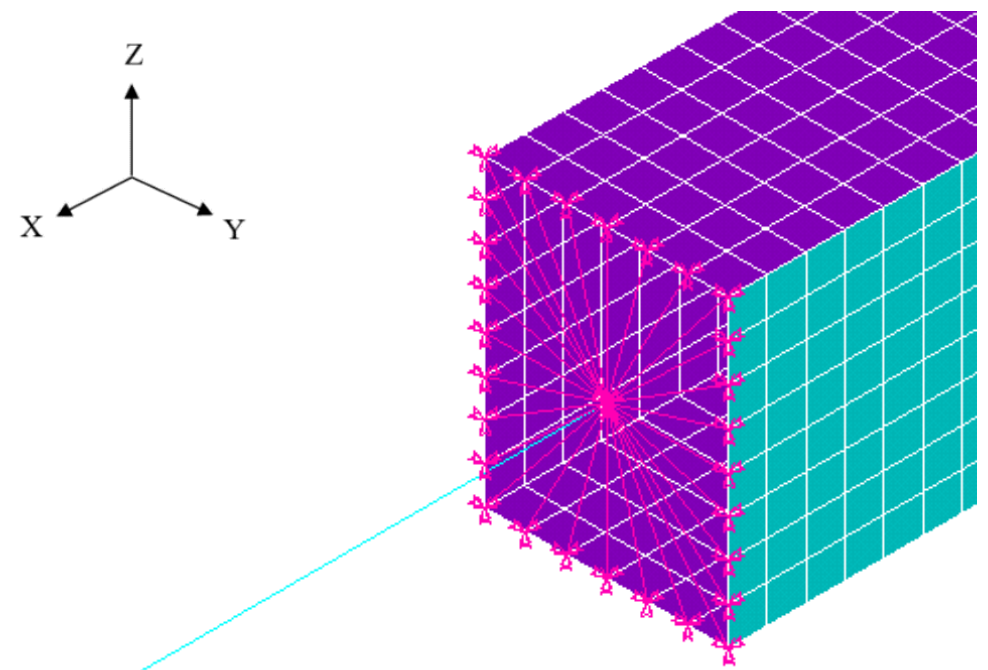

Figura 12 - Detalhe região rígida Fonte: Castro (2018).

Para a reprodução das condições de apoio da coluna, selecionaram-se os nós das extremidades da mesma os quais foram aplicados as restrições nodais às translações UX, UY, UZ e às rotações ROTX, ROTY e ROTZ. Foi ainda restringida a extremidade de cada viga na direção lateral (Y), para reproduzir as condições experimentais de Silva (2006), evitando deslocamentos nesta direção, conforme Figura 13. 


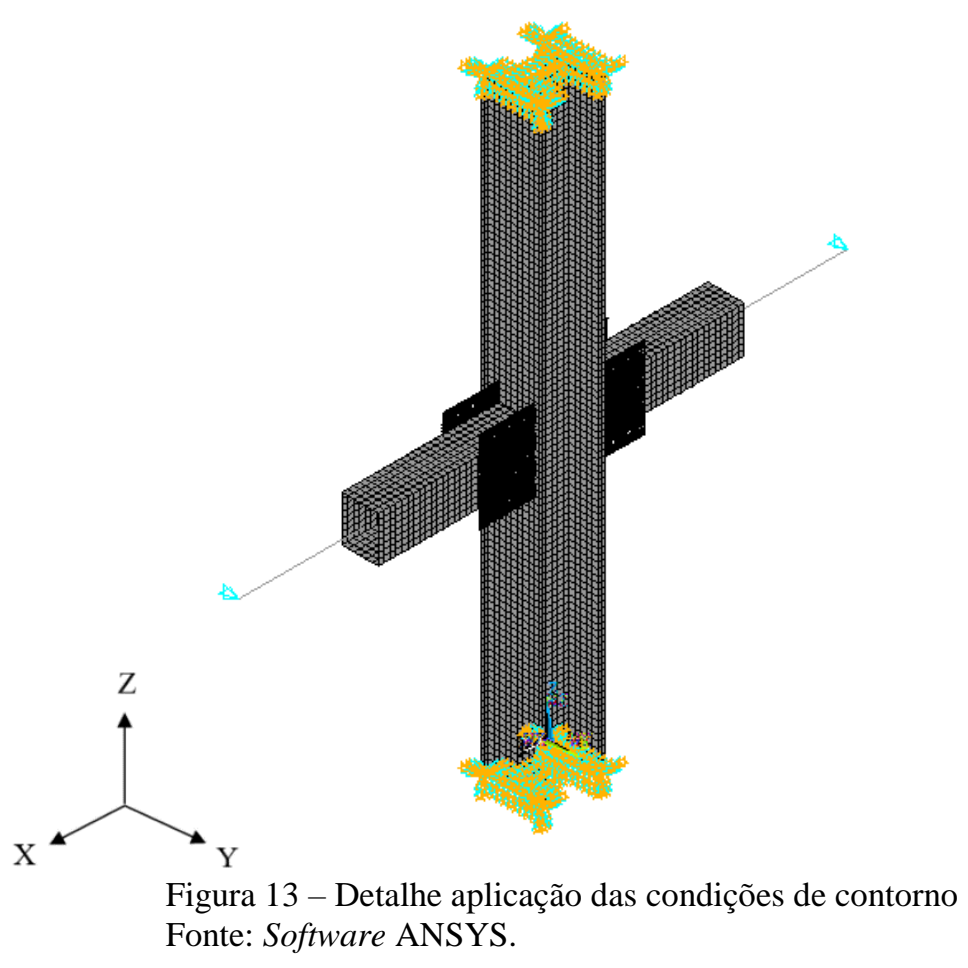

A análise consistiu na aplicação da força de $20 \mathrm{kN}$ em cada extremidade das vigas em incrementos de força, nos quais cada subpasso representou um incremento de $10 \%$ da força total, conforme Figura 14. Após análise, foram extraídos do modelo os resultados dos deslocamentos verticais das extremidades das vigas chamadas de viga 1 e viga 2, procedimento utilizado no ensaio experimental. Dessa forma, foi possível traçar as curvas força-deslocamento do modelo e fazer a comparação com as curvas obtidas dos resultados experimentais de Silva (2006).

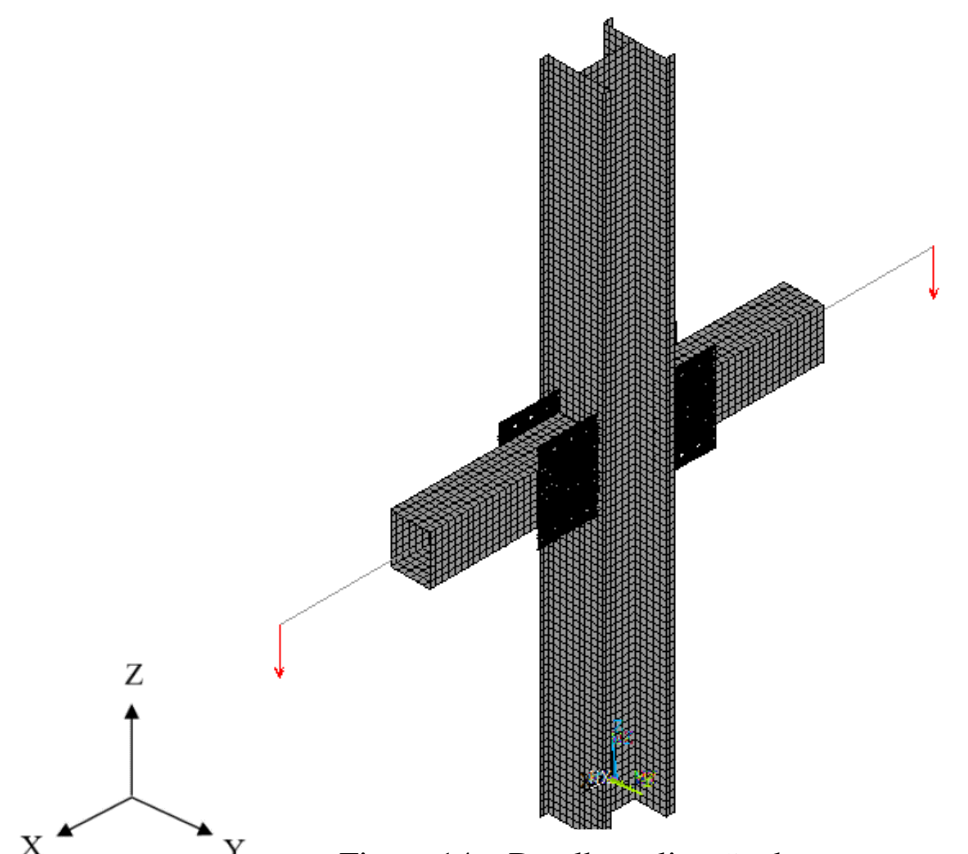

Figura 14 - Detalhe aplicação do carregamento Fonte: Software ANSYS.

ForSci.: r. cient. IFMG, Formiga, v. 7, n. 2, e00652, jul./dez. 2019. 


\section{RESULTADOS}

\subsection{Deslocamentos}

Na Figura 15, são apresentados os deslocamentos verticais do protótipo. Vê-se que, conforme esperado, as extremidades das vigas em balanço apresentam maiores deslocamentos.

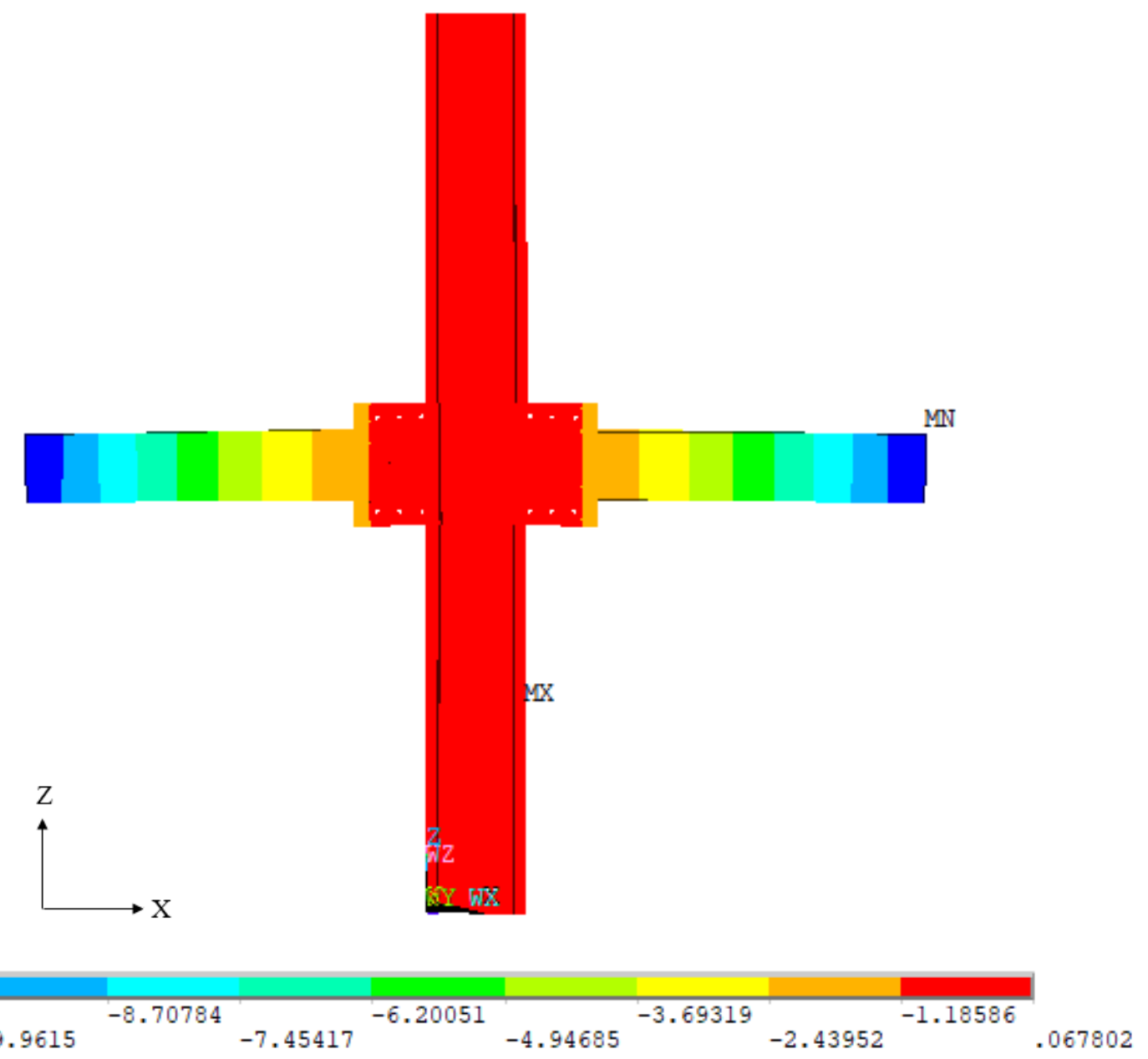

Figura 15 - Resultados dos deslocamentos verticais no modelo analisado Fonte: Software ANSYS.

Com as curvas apresentadas na Figura 16, pode ser vista a comparação entre os resultados numéricos e experimentais em função das forças e deslocamentos. As curvas obtidas para viga 1 e viga 2 são coincidentes devido às simetrias geométrica e de carregamento do modelo numérico. Os resultados numéricos obtidos pela análise não linear levam a valores de deslocamentos inferiores aos obtidos no ensaio experimental. Esta diferença pode ser explicada pela existência de folgas no modelo real na região dos parafusos 
que não foram consideradas no modelo numérico, uma vez que foi considerado, a fim de simplificar o modelo, o acoplamento total dos deslocamentos dos nós nestas regiões. No entanto, o modelo numérico apresenta uma tendência similar à observada experimentalmente, indicando sua viabilidade em uma análise do comportamento da ligação.

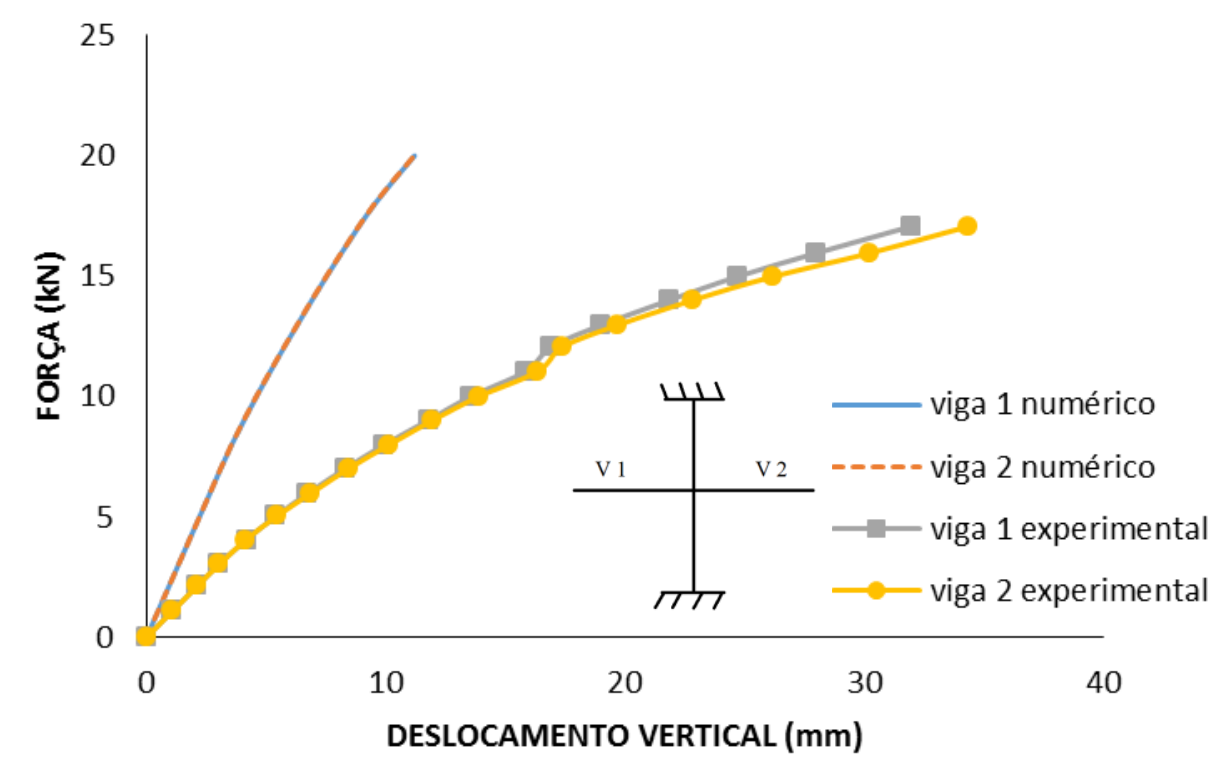

Figura 16 - Curvas força-deslocamento análise numérica e experimental Fonte: Castro (2018).

\subsection{Tensões}

O limite de escoamento é importante na análise de tensões, visto que, a partir deste valor, ocorrem os efeitos de deformações permanentes e plastificação das seções (UGURAL; FENSTER, 2011). Dessa forma a extensão da deformação inelástica que precede a falha da estrutura depende muito do material envolvido. Assim, a utilização de materiais com diferentes limites de escoamento reflete diretamente no comportamento e desempenho da ligação, cada elemento contribuindo individualmente na propagação de tensões em diversos pontos da estrutura, podendo em alguns casos atingir o colapso antes do limite de escoamento do restante da estrutura. Dessa forma, foi importante analisar a evolução das tensões de Von Mises para cada elemento estrutural separadamente.

Na Figura 17, apresentam-se as tensões desenvolvidas nas colunas. Observa-se que as maiores tensões desenvolvem-se na região central, onde existe o reforço de coluna, o que indica a sua importância para a ligação. 


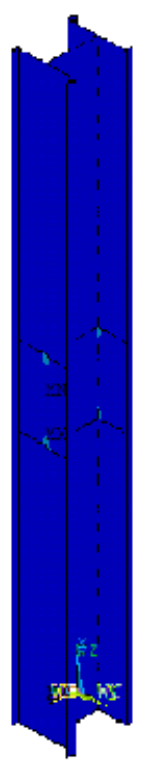

(a)

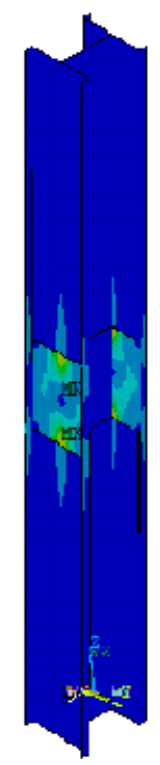

(b)

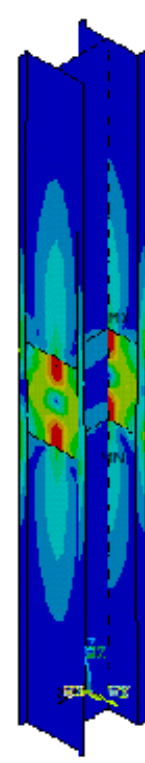

(c)

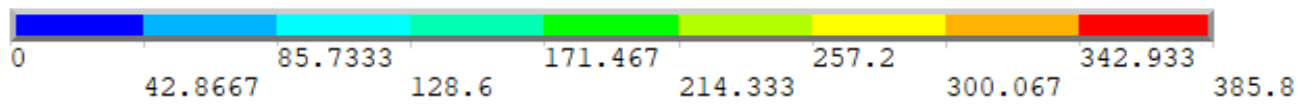

Figura 17 - Tensões de Von Mises para carga $\mathrm{P}=2 \mathrm{kN}$ (a), $\mathrm{P}=10 \mathrm{kN}$ (b) e $\mathrm{P}=20 \mathrm{kN}$ (c) Fonte: Software ANSYS.

Na Figura 18, apresentam-se as tensões desenvolvidas nas cantoneiras. Observa-se que as maiores tensões desenvolvem-se no primeiro furo mais externo da cantoneira, ou seja, aquele mais afastado da alma da coluna. Este comportamento é coerente, uma vez que o primeiro parafuso é o mais solicitado e o gráfico de tensões das vigas, apresentado na Figura 19, corrobora esta observação, pois a região mais solicitada deste componente corresponde à região mais solicitada da cantoneira.

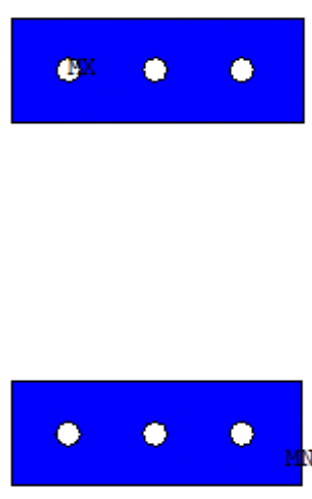

(a)
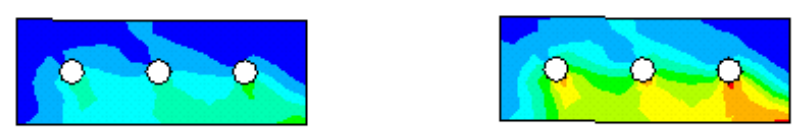

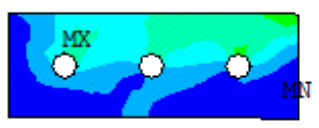

(b)

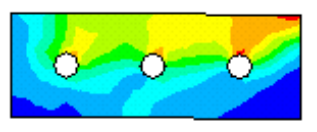

(c)

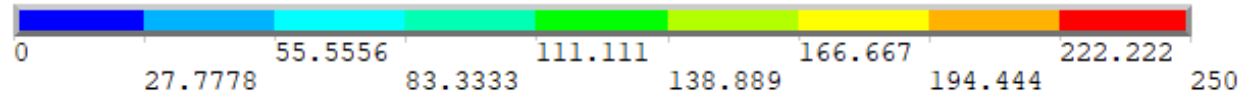

Figura 18 - Tensões de Von Mises para carga $\mathrm{P}=2 \mathrm{kN}$ (a), $\mathrm{P}=10 \mathrm{kN}$ (b) e $\mathrm{P}=20 \mathrm{kN}$ (c) Fonte: Software ANSYS. 


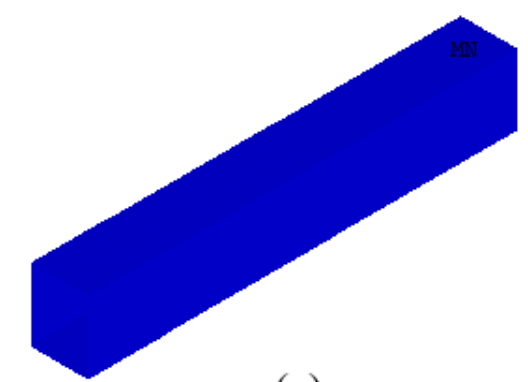

(a)

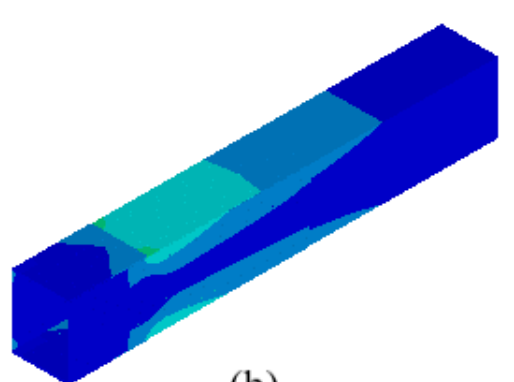

(b)

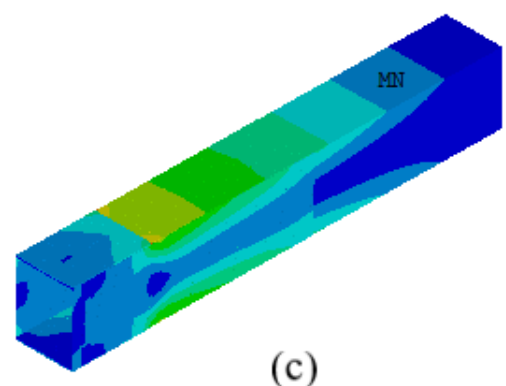

(c)

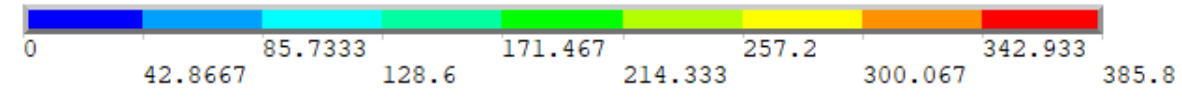

Figura 19 - Tensões de Von Mises para carga $\mathrm{P}=2 \mathrm{kN}$ (a), $\mathrm{P}=10 \mathrm{kN}$ (b) e $\mathrm{P}=20 \mathrm{kN}$ (c) Fonte: Software ANSYS.

Na Figura 20, observam-se as tensões de Von Mises na chapa de suporte. Percebe-se que, devido ao fato de a sua espessura ser maior que a das cantoneiras, o desenvolvimento de tensões neste elemento não atinge o escoamento, como ocorre naquelas.

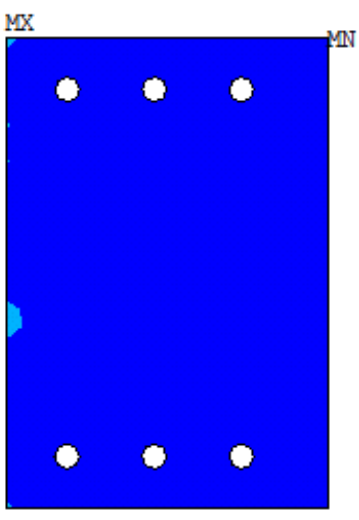

(a)

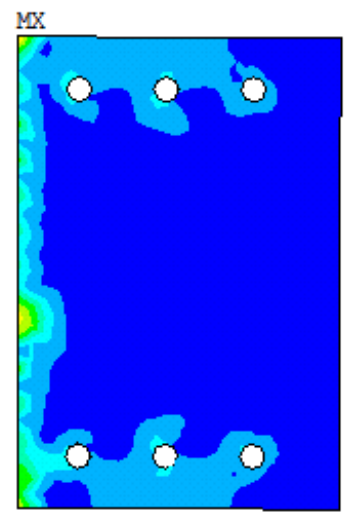

(b)

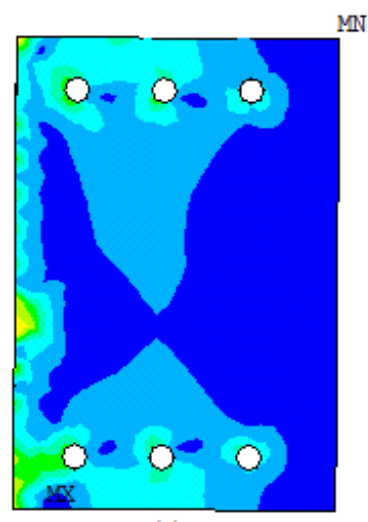

(c)

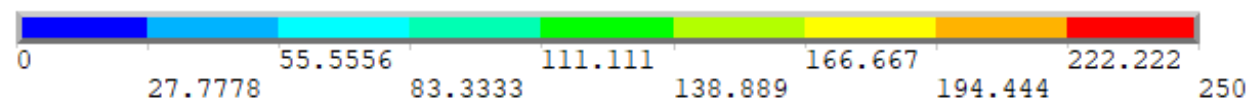

Figura 20 - Tensões de Von Mises para carga $\mathrm{P}=2 \mathrm{kN}$ (a), $\mathrm{P}=10 \mathrm{kN}$ (b) e $\mathrm{P}=20 \mathrm{kN}$ (c) Fonte: Software ANSYS.

\section{CONCLUSÃO}

Os perfis formados a frio possibilitam a construção de estruturas metálicas de forma econômica. No entanto, por serem estruturas esbeltas, apresentam muitas particularidades que tornam a análise do seu comportamento mais complexa.

Entre as soluções propostas, está a ligação parafusada, objeto deste trabalho. Visando a economia na análise, foi construído um modelo via elementos finitos, a partir de resultados 
obtidos experimentalmente. Os resultados indicaram que o modelo numérico é cerca de duas vezes mais rígido que o modelo experimental, indicando a necessidade de ajustes no modelo, como a modelagem utilizando o perfil caixa com a espessura real, os parafusos e a redução das simplificações.

Apesar disto, o modelo via elementos finitos permite uma análise do comportamento da ligação, indicando possíveis pontos de ruptura nas regiões mais solicitadas. Observou-se que o reforço utilizado nas colunas é fundamental, por ser esta região uma zona com elevada concentração de tensões de plastificação. Observou-se também que as cantoneiras utilizadas na ligação apresentam a mesma característica, sendo um dos componentes fundamentais para o bom funcionamento da ligação.

\title{
NUMERICAL ANALYSIS OF SEMI-RIGID BOLT CONNECTION IN COLD FORMED PROFILES
}

\begin{abstract}
The current paper is based on a numerical analysis by means of finite elements aiming at the software reproduction of an experimental test of semi-rigid bolt connection in cold formed profiles occurred in the three-dimensional scope. The analysis consisted of the reproduction of the prototype geometry, the boundary conditions, and the loading application. For a better forecast of the connection behavior, physical and geometric non-linearity were inserted to the model. The force-displacement curves and the evolution of the Von Mises stresses for the different prototype components were obtained. The results indicated that the numerical model is about twice as rigid as the experimental one. However, it was possible to observe that the behavior of the numerical model has a similar tendency if compared to the experimental model and it was still possible to evaluate the contribution of the connection elements to its performance.
\end{abstract}

Keywords: Numerical analysis. Semi-rigid bolt connection. Cold-formed profiles. Structural performance.

\section{REFERÊNCIAS}

AMERICAN INSTITUTE OF STEEL CONSTRUCTION. Specification for structural steel buildings, ANSI/AISC 360-16: Chicago, 2016.

ANSYS ${ }^{\circledR}$ Structural Analysis, release 15.0, Help System. Mechanical APDL Structural Analysis Guide. ANSYS, Inc., Canonsburg, PA. 2013, 522 p. 
ASSOCIAÇÃO BRASILEIRA DE NORMAS TÉCNICAS. Dimensionamento de estruturas de aço constituídas por perfis formados a frio, ABNT NBR 14762: Rio de Janeiro, 2010.

CASTRO, Emerson Cardoso de. Análise numérica de ligações parafusadas semirrígidas em perfis formados a frio. 2018. 90 f. Dissertação (Mestrado em Construção Metálica) Universidade Federal de Ouro Preto, Ouro Preto, 2018.

LEE, Yeong Huei; TAN, Cher Siang; MOHAMMAD, Shahrin; TAHIR, Mahmood Md; SHEK, Poi Ngian. Review on cold-formed steel connections. The Scientific World Journal, Cairo, v. 2014, p. 1-11, 2014.

MACHADO, Ana Paula Magalhães. Análise numérica de ligações do sistema de armazenagem industrial. 2018. 65 f. Dissertação (Mestrado em Construção Metálica) Universidade Federal de Ouro Preto, Ouro Preto, 2018.

MORAIS, Cassius Soares. Análise teórico-experimental de ligações parafusadas em perfis formados a frio. 2003. $301 \mathrm{f}$. Dissertação (Mestrado em Engenharia Civil). Escola de Minas, Universidade Federal de Ouro Preto, Ouro Preto, 2003.

SANTOS, Luciano Barbosa dos. Influência da rigidez das ligações em estruturas de aço. 1998. 173 f. Dissertação (Mestrado em Engenharia de Estruturas) - Universidade de São Paulo, São Carlos, 1998.

SILVA, Alexandre Camillo da. Estudo de ligações parafusadas em perfis formados a frio. 2006. 156 f. Dissertação (Mestrado em Engenharia Civil) - Universidade Federal de Ouro Preto, Ouro Preto, 2006.

SILVA, Alexandre Camillo da; FREITAS, Arlene Maria Sarmanho. Análise teóricoexperimental de ligações parafusadas com enrijecedores de alma em perfis de aço formados a frio. Revista Escola de Minas, Ouro Preto, v. 61, n. 2, p. 231-237, 2008.

SILVA, Adriano Toledo. Ligações semirrígidas em perfis formados a frio de aço. 2017. 123 f. Dissertação (Mestrado em Engenharia Civil) - Universidade Federal de Ouro Preto, Ouro Preto, 2017.

SILVA, Valdir Pignatta e; RODRIGUES, Francisco Carlos; FAKURY, Ricardo Hallal; PANNONI, Fábio Domingos. Incêndio real em apartamento de interesse social - um estudo de caso. Revista Escola de Minas, Ouro Preto, v. 60, n. 2, p. 315-324, 2007.

SOUZA, Flávio Teixeira de. Análise teórico-experimental da estabilidade de colunas perfuradas em perfis de aço formados a frio de seções tipo rack. 2013. $209 \mathrm{f}$. Tese (Doutorado em Engenharia Civil) - Universidade Federal de Ouro Preto, Ouro Preto, 2013.

UGURAL, Ansel C.; FENSTER, Saul K. Advanced mechanics of materials and applied elasticity. 5. ed. Boston: Pearson Education, Inc., 2011.

YU, Wei-Wen. Cold-formed steel design. 3. ed. New York: John Wiley \& Sons, Inc., 2000. 


\section{DADOS DOS AUTORES}

\section{Emerson Cardoso de Castro}

E-mail: emersoncastro@outlook.com

Currículo Lattes: http://lattes.cnpq.br/1012108465600208

Bacharel em Engenharia Civil pela Universidade Federal de Minas Gerais (2009), Mestre em Construção Metálica pela Universidade Federal de Ouro Preto (2018). Experiência profissional no setor privado profissional com elaboração de projetos de sistemas de coberturas metálicas e galpões comerciais e industriais com perfis formados a frio e de alma corrugada. Experiência no setor público como profissional de engenharia atuando como agente fiscalizador de obras públicas, avaliação e elaboração de projetos e orçamentos de obras civis para fim institucional inclusive emissão de laudos e pareceres técnicos.

\section{Flávio Teixeira de Souza}

E-mail: flavio.souza@ifmg.edu.br

Currículo Lattes: http://lattes.cnpq.br/6644014573906423

Possui graduação em Engenharia Civil pela Universidade Federal de Ouro Preto (2002), mestrado em Engenharia Civil pela Universidade Federal de Ouro Preto (2005) e doutorado em Engenharia Civil pela Universidade Federal de Ouro Preto (2013). Atualmente é prof. de ensino básico, técnico e tecnológico do Instituto Federal Minas Gerais. Tem experiência na área de Engenharia Civil, com ênfase em Estruturas Metálicas, atuando principalmente nos seguintes temas: elementos finitos, estrutura metálica, estruturas metálicas, perfis formados a frio e perfis formados a frio perfurados.

\section{Arlene Maria Cunha Sarmanho}

E-mail: arlene.sarmanho@gmail.com

Currículo Lattes: http://lattes.cnpq.br/2282392116347497

Engenheira Civil, possui Mestrado (1991) e Doutorado (1996) em Engenharia Civil pela COPPE/Universidade Federal do Rio de Janeiro. Atualmente é professora Associado da Universidade Federal de Ouro Preto, consultora do CNPq, CAPES, Coordenadora pela UFOP do convênio de Pesquisa e Desenvolvimento (P\&D) com a Vallourec Mannesmann do Brasil, Coordenadora de projeto e sub-projeto com a FINEP - Financiadora de Estudos e Projetos, membro do corpo editorial - Revista Escola de Minas, professora colaboradora na Universidade Estadual de Campinas, Consultora do CBCA. Tem experiência na área de Engenharia Civil, com ênfase em Estruturas Metálicas, atuando principalmente nos seguintes temas: estruturas metálicas e mistas, perfis formados a frio, análise experimental e estabilidade estrutural. 